\title{
Co-registro de dados ópticos em Ressonância Magnética para aplicações em Neurociências
}

\author{
Hitalo Rodrigues Mendes (IC), Rickson Coelho Mesquita (PQ)
}

\begin{abstract}
Resumo
A espectroscopia no infravermelho próximo (NIRS) é uma técnica inovadora em neuroimagem. Embora esteja bem estabelecida, a NIRS tem a desvantagem de ter baixa resolução espacial. Este projeto teve como principal objetivo auxiliar no melhoramento da resolução espacial de medidas de NIRS em neuroimagem através do desenvolvimento da sistematização no processo de localização de fontes e detectores usando imagens de ressonância magnética e um sistema de escaneamento.
\end{abstract}

Palavras Chave: Ressonância Magnética, NIRS, Neuroimagem.

\section{Introdução}

A capacidade de observar a ativação funcional do cérebro cresceu nos últimos anos, especialmente devido ao desenvolvimento de técnicas não invasivas. Entre elas, Espectroscopia do Infravermelho Próximo (NIRS) tem um destaque. Esta técnica emergente usa o princípio de difusão de fótons para monitorar a atividade do cérebro. Embora esteja relativamente bem estabelecida, a técnica de NIRS apresenta algumas desvantagens sendo umas delas a baixa resolução espacial.

Uma solução para este problema é a sistematização do processo de localização de fontes e detectores no escalpo, com o apoio de um sistema comercial de escaneamento e desenvolvimento de um software de controle.

\section{Resultados e Discussão}

A sistematização é feita usando uma transformação entre dois sistemas de referência, um sendo o de sistema de escaneamento e o outro é o sistema de referência de uma imagem de ressonância magnética (MRI).

Para tal transformação ser feita é necessária a aquisição de pontos nos dois sistemas de referência e em seguida é usado um algoritmo de mínimos quadrados ${ }^{1}$.

Antes de fazer a MRI são feitas marcações com cápsulas de vitamina $\mathrm{E}$ para que possam ser vistos na imagem (Figura 1). Após a realização da MRI estes mesmos pontos são adquiridos com o auxílio do sistema de escaneamento.

A validação é feita fazendo a transformação usando os pontos pré-auricular direito e esquerdo e o nasal, assim como alguns pontos do escalpo. Em seguida foram utilizados os pontos no escalpo que não foram utilizados na transformação para determinar a distância euclidiana (erro) entre o valor esperado para os pontos e o obtido com a transformação.

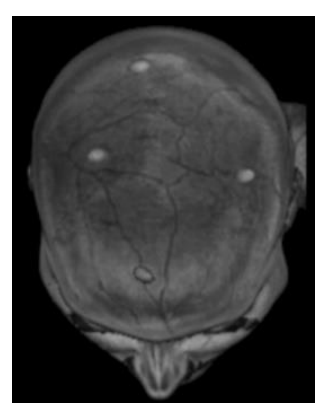

Figura 1. Visão superior MRI mostrando as capsulas de vitamina E.

Foi percebido que o erro teve um valor muito grande, que foi diminuindo conforme o número de pontos usados na transformação aumentava. $O$ motivo para um valor muito grande para o erro é que os pontos precisam ser exatamente os mesmos nos dois referenciais para que a transformação seja precisa. No entanto, é quase impossível coletar os mesmos pontos no espaço do sistema de escaneamento e da MRI ${ }^{2}$.

\section{Conclusões}

Os resultados mostram a necessidade de um grande número de pontos para que o erro seja diminuído. Portanto sempre deve ser usado o máximo de pontos, para que o erro seja aceitável. No caso de NIRS o valor aceitável para o erro é ser menor que $3 \mathrm{~cm}$, pois esta é a distância média que a luz percorre antes de chegar no detector.

\footnotetext{
ARUN, K. Somani; HUANG, Thomas S.; BLOSTEIN, Steven D. Least-squares fitting of two 3-D point sets. Pattern Analysis and Machine Intelligence, IEEE Transactions on, n. 5, p. 698-700, 1987.

${ }^{2}$ PERES, André Salles Cunha. Implementação de um sistema de localização espacial de regiões cerebrais em tempo real para aplicação de TMS por co-registro com fMRI. 2008. Tese de Doutorado. Universidade de São Paulo.
} 